\title{
Risk factors for acute kidney injury among patients with chikungunya: a multi-center experience from the 2017 chikungunya outbreak in Dhaka, Bangladesh
}

\author{
Zaman $\mathrm{S}^{\mathrm{a}}$, Rahim MA ${ }^{\mathrm{b}}$, Jahan $\mathrm{I}^{\mathrm{c}}$, Chowdhury TA ${ }^{\mathrm{d}}$, Ananna MA ${ }^{\mathrm{b}}$, Iqbal S ${ }^{\mathrm{e}}$, \\ Uddin $\mathrm{KN}^{\mathrm{f}}$, Latif $\mathrm{ZA}^{\mathrm{g}}$
}

\begin{abstract}
Background: Chikungunya is an emerging viral infection in Bangladesh. This self-limiting febrile illness may have acute life-threating features including cardiomyopathy and encephalitis. Acute kidney injury (AKI) is less well described complication of chikungunya. This study was designed to evaluate risk factors for AKI among patients with chikungunya virus infection.

Methods: This case-control study was done in 3 different centers in Dhaka, Bangladesh from July to October 2017. Adult patients (>18 years) with confirmed diagnosis of chikungunya were included in this study. AKI was diagnosed as per Kidney Disease: Improving Global Outcomes (KDIGO) Clinical Practice Guideline for Acute Kidney Injury. Patients suffering from chikungunya complicated by AKI were cases and those without AKI were controls.

Results: Total patients were 107 (male 61) with a mean age of 35.6 (range 19-84) years. Common comorbidities were diabetes mellitus (DM) (20.6\%), hypertension (17.8\%) and chronic kidney disease (CKD) (12.1\%). Common presentations included fever (86.9\%) or recent history of fever (13.1\%), joint pain (88.8\%), rash (23.4\%), pruritus (15.9\%), gastro-intestinal (GI) features like diarrhea and/or vomiting (28\%), lymphadenopathy (12.1\%), gum swelling/oral ulcer (4.1\%) and oedema (8.4\%). Fourteen (13.1\%) patients required hospitalization. Eleven (10.3\%) cases were complicated by AKI. Among the risk factors for AKI, comorbidities like DM (OR 28.73, 95\% CI 5.57-148.10, $p$ 0.0001) and CKD (OR 31.0, 95\% CI 2.94-326.7, p <0.0001), GI features (OR 16.07, 95\% CI 3.22-80.14, p 0.0007), requirement of hospitalization (OR 23.10, 95\% CI 2.37-226.31, $p<0.0001)$ and use of angiotensin converting enzyme inhibitors/angiotensin receptor blockers (ACEIS/ARBS) (OR 6.65, 95\% CI 1.77-24.98, p 0.005) were significant.

Conclusions: One-tenth of adult patients suffering from chikungunya were complicated by AKI in this study. $D M, C K D$, diarrhea and/or vomiting, hospitalization and use of ACEIS/ARBs appeared as significant risk factors for $A K I$.
\end{abstract}

Key words: acute kidney injury, Bangladesh, chikungunya, Dhaka outbreak, risk factors.

(BIRDEM Med J 2019; 9(3): 193-196)

\footnotetext{
Author information

a. Shahana Zaman, Junior Consultant, Cardiology, NICVD, Dhaka, Bangladesh.

b. Muhammad Abdur Rahim, Mehruba Alam Ananna, Associate Professor, Nephrology, BIRDEM General Hospital, Dhaka, Bangladesh.

c. Ishrat Jahan, Assistant Registrar, Nephrology, BIRDEM General Hospital, Dhaka, Bangladesh.

d. Tufayel Ahmed Chowdhury, Registrar, Nephrology, BIRDEM General Hospital, Dhaka, Bangladesh.

e. Sarwar Iqbal, Professor, Nephrology, BIRDEM General Hospital, Dhaka, Bangladesh.

f. Khwaja Nazim Uddin, Professor, Internal Medicine, BIRDEM General Hospital, Dhaka, Bangladesh.

g. Zafar Ahmed Latif, Professor, Endocrinology and Director General, BIRDEM General Hospital, Dhaka, Bangladesh.

Address of correspondence: Shahana Zaman, Junior Consultant, Cardiology, NICVD, Dhaka, Bangladesh. Email: banee2003@yahoo.com, muradrahim23@yahoo.com

Received: August 31, 2018

Accepted: July 31, 2019
} 


\section{Introduction}

Chikungunya is one of the most rapidly spreading mosquito-borne viral infections of global concern. ${ }^{1}$ In Bangladesh, it is an emerging infection. ${ }^{2}$ Generally, chikungunya is a self-limiting disease with fever and arthritis/arthralgia being the two most common features. ${ }^{1,2}$ Chikungunya may have prolonged rheumatological complications and acute life-threating features including cardiomyopathy and encephalitis. ${ }^{1}$ Acute kidney injury $(\mathrm{AKI})^{3}$ and nephritis ${ }^{4}$ are less well described complications of chikungunya. As patients with chikungunya may require non-steroidal antiinflammatory drugs (NSAIDs) ${ }^{2}$ for pain management, they may develop drug induced AKI as well. This study was designed to evaluate the frequency of AKI among patients with chikungunya and to evaluate associated risk factors in a chikungunya cohort of the 2017 chikungunya outbreak in Dhaka, Bangladesh.

\section{Methods}

This case-control study included patients from 3 different hospitals in Dhaka, the capital city of Bangladesh namely Bangladesh Institute of Research and Rehabilitation in Diabetes, Endocrine and Metabolic Disorders (BIRDEM) General Hospital (14), Gulshan Maa O Shishu Clinic Pvt. Ltd. (64) and LabAid Gulshan (29) from July 1, 2017 to October 31, 2017. Adult patients (>18 years) with confirmed diagnosis of chikungunya ${ }^{5}$ were included in this study. AKI was diagnosed as per Kidney Disease: Improving Global Outcomes (KDIGO) Clinical Practice Guideline for Acute Kidney Injury. ${ }^{6}$ Patients suffering from chikungunya complicated by AKI were cases and those without AKI were controls. Increasing age, presence of diabetes mellitus (DM), chronic kidney disease (CKD), gastrointestinal (GI) symptoms including diarrhea and/ or vomiting, requirement of hospitalization in severe cases, concomitant use of angiotensin converting enzyme inhibitors/angiotensin receptor blockers (ACEIs/ARBs) and NSAIDs were evaluated as possible risk factors for AKI.

\section{Results}

Total patients were 107 (male 61, female 46) with a mean age of 35.6 (range 19-84) years. Over two-thirds $(74,69.2 \%)$ of the patients were from Dhaka North City Corporation and rest $(33,30.8 \%$ ) were from Dhaka South City Corporation.

Common comorbidities were DM (22, 20.6\%), hypertension $(19,17.8 \%)$, CKD (13, 12.1\%), dyslipidaemia $(11,10.3 \%)$, fatty liver disease $(9,8.4 \%)$ and ischaemic heart disease $(7,6.5 \%)$. Common presentations included fever $(93,86.9 \%)$ or recent history of fever $(14,13.1 \%)$, joint pain $(95,88.8 \%)$, rash $(25$, $23.4 \%)$, pruritus $(17,15.9 \%)$, diarrhea and/or vomiting (30, 28\%), lymphadenopathy $(13,12.1 \%)$, gum swelling and/or oral ulcer $(5,4.1 \%)$ and oedema $(9,8.4 \%)$. Two patients had chikungunya-dengue co-infections. ${ }^{7,8}$ Most $(93,86.9 \%)$ patients were managed as out-patient basis while $14(13.1 \%)$ patients required hospitalization.

Eleven (10.3\%) cases were complicated by AKI. Risk factors for AKI included increasing age, comorbidities like DM ( $p$ $0.0001)$, CKD ( $<<0.0001)$, diarrhea and/or vomiting ( $p$ $0.0007)$, requirement of hospitalization $(\mathrm{p}<0.0001)$, use of ACEIs/ARBs (p 0.005) and NSAIDs (Table I).

Table I Risk factors for AKI among patients with chikungunya ( $\mathrm{N}=107)$

\begin{tabular}{|c|c|c|c|c|}
\hline Risk factors & & AKI (11) & No AKI (96) & Odds ratio, $95 \% \mathrm{CI}, \mathrm{p}$ value \\
\hline \multirow[t]{2}{*}{ Age $(>55$ years $)$} & Yes (46) & 7 & 39 & $2.55,0.70-9.33,0.1550$ \\
\hline & No $(61)$ & 4 & 57 & \\
\hline \multirow[t]{2}{*}{ DM } & Yes (22) & 9 & 13 & $28.73,5.57-148.10,0.0001$ \\
\hline & No $(85)$ & 2 & 83 & \\
\hline \multirow[t]{2}{*}{ CKD } & Yes (13) & 10 & 3 & $31.00,2.94-326.71,<0.0001$ \\
\hline & No $(94)$ & 1 & 93 & \\
\hline \multirow[t]{2}{*}{ Presence of GI symptoms } & Yes (30) & 9 & 21 & $16.07,3.22-80.14,0.0007$ \\
\hline & No (77) & 2 & 75 & \\
\hline \multirow[t]{2}{*}{ Required hospitalization } & Yes (14) & 10 & 4 & $23.10,2.37-226.31,<0.0001$ \\
\hline & No (93) & 1 & 92 & \\
\hline \multirow[t]{2}{*}{ Use of ACEI/ARB } & Yes (27) & 7 & 20 & $6.65,1.77-24.98,0.0050$ \\
\hline & No $(80)$ & 4 & 76 & \\
\hline \multirow[t]{2}{*}{ Use of NSAIDs } & Yes (9) & 2 & 7 & $2.88,0.51-15.69,0.2351$ \\
\hline & No $(98)$ & 9 & 89 & \\
\hline
\end{tabular}




\section{Discussion}

AKI is common in community and in hospital settings and may have diverse aetiology. ${ }^{9-12}$ Chikungunya viral infections have few but life threating acute complications like encephalitis ${ }^{13}$ and cardiomyopathy ${ }^{14}$, but nephritis ${ }^{4}$ is rarely reported. Infection associated glomerulonephritis and AKI is common in tropics ${ }^{15-17}$, but as an aetiology, chikungunya ${ }^{3,18}$ is occasionally mentioned. We assume, as a cause of AKI, chikungunya is a potential candidate because patients may have GI symptoms causing volume depletion and pre-renal AKI, they are prone to develop NSAIDs induced AKI as many patients are likely to require pain killers ${ }^{2}$ in acute chikungunya arthritis.

In the present chikungunya cohort, one-tenth of patients developed AKI, but this ratio rises to over two-thirds $(10 / 14,71.4 \%)$ when calculated among patients who required hospitalization, which is much higher than overall incidence of AKI in hospital settings, even if we compare with AKI incidence in intensive care units. ${ }^{10,11}$

Patients with DM are at increased risk for AKI than non-diabetic counterparts ${ }^{19}$ which was also evident in the present study. CKD is also a risk factor for AKI. ${ }^{20}$ Thirteen of our patients had pre-existing CKD and 10 $(10 / 13,76.9 \%)$ of them were complicated by AKI.

Diarrhea and vomiting causes intravascular volume depletion and if not properly replaced by oral or intravenous route (if required), they may be complicated by AKI. ${ }^{21}$ This is more common in cholera and other causes of acute gastro-enteritis, but also appeared to be true in our chikungunya cohort. In the setting of surgery and volume depletion, concomitant medications like ACEIs/ARBs need to be revised, at least for a temporary basis, as haemodynamic alteration predisposes these patients to $\mathrm{AKI} .^{22}$ One-third of our patients, who were receiving ACEIs or ARBs had AKI while this ratio was only one-nineteenth among those not receiving such drugs.

NSAIDs are well recognized cause for AKI. Chikungunya characteristically cause arthritis/arthralgia along with fever. ${ }^{2}$ Nearly ninety percent of patients had joint pain in this chikungunya cohort. Initially they were managed with paracetamol, but nine patients required NSAIDs for pain management. Two $(2 / 9,22.2 \%)$ had AKI while $9(9 / 98,9.2 \%)$ patients who did not require NSAIDs developed AKI. So, use of NSAIDs in chikungunya arthritis was not proved to be a significant risk factor for AKI in this study, which may be due to small sample size in our cohort.

In conclusion, one-tenth of patients suffering from chikungunya were complicated by AKI in this study and comorbidities like DM and CKD, presence of GI symptoms like diarrhea and/or vomiting, requirement of hospitalization and concomitant use of ACEIs/ARBs appeared as significant risk factors for AKI. So, patients with DM, CKD and those receiving ACEIs/ARBs should be warned for possible development of AKI, if they acquire chikungunya viral infection and suggested for adequate fluid replacement in case of diarrhea and vomiting.

Conflict of interest: Nothing to declare.

\section{References}

1. Weaver SC, Lecuit M. Chikungunya virus and the global spread of a mosquito-borne disease. N Engl J Med 2015; 372:1231-1239.

2. Rahim MA, Uddin KN. Chikungunya: an emerging viral infection with varied clinical presentations in Bangladesh: Reports of seven cases. BMC Res Notes 2017; 10: 410.

3. Hamid A, Dhrolia MF, Qureshi R, Imtiaz S, Ahmad A. Acute Kidney Injury Secondary to Rhabdomyolysis: A Rare Presentation of Chikungunya Fever. J Coll Physicians Surg Pak 2018;28(6):S94-S96.

4. Dueymes J, Liegeon G, Dione L, Ferlicot S, Molinie V. Acute tubulointerstitial nephritis in chikungunya fever: first cases proven by renal biopsy. ISN Academy. 2015; 153539. (published on line March 15, 2015)

5. Directorate General of Health Services (DGHS), Ministry of Health \& Family Welfare. Government of People's Republic of Bangladesh. Bangladesh National Guideline on Clinical Management of Chikungunya Fever; 2017.

6. Kidney Disease: Improving Global Outcomes (KDIGO) Acute Kidney Injury Work Group. KDIGO Clinical Practice Guideline for Acute Kidney Injury. Kidney Inter (Suppl.) 2012;2:1-138

7. Rahim MA, Zaman S, Sultana N, Islam A, Uddin KN. Chikungunya-dengue co-infection during pregnancy requiring preterm Caesarean section: first case report from Bangladesh. Trop Doct 2018;48(3):234-235.

8. Rahim MA, Zaman S, Afroze SR, Haque HF, Afroz F, Samad $\mathrm{T}$, et al. Chikungunya virus and dengue virus coinfection: a case report from Bangladesh. IMC J Med Sci 2018;12(1):4243.

9. Samad T, Haque WMM, Rahim MA, Iqbal S, Mitra P. Community Acquired Acute Kidney Injury from Edible Agents: Report from a Developing Country, Bangladesh. The Open Urology \& Nephrology Journal 2017;10:20-28. 
10. Challiner R, Ritchie JP, Fullwood C, Loughnan P, Hutchison AJ. Incidence and consequence of acute kidney injury in unselected emergency admissions to a large acute UK hospital trust. BMC Nephrology 2014;15:84.

11. Case J, Khan S, Khalid R, Khan A. Epidemiology of Acute Kidney Injury in the Intensive Care Unit. Critical Care Research and Practice 2013; Article ID 479730.

12. Yang F, Zhang L, Wu H, Zou H, Du Y. Clinical Analysis of Cause, Treatment and Prognosis in Acute Kidney Injury Patients. PLoS ONE 2014;9(2): e85214.

13. de Oliveira Sá PK, de Miranda Nunes M, Leite IR, das Chagas Campelo MGL, Leão CFR, de Souza JR, et al. Chikungunya virus infection with severe neurologic manifestations: report of four fatal cases. Rev Soc Bras Med Trop 2017;50(2):265268.

14. Rajapakse S1, Rodrigo C, Rajapakse A. Atypical manifestations of chikungunya infection. Trans R Soc Trop Med Hyg 2010;104(2):89-96.

15. Wiwanitkit S, Wiwanitkit V. Renal failure due to important arbovirus infection: A short summary. Saudi J Kidney Dis Transpl 2017;28:1206-1208.
16. Mathewa AJ, George J. Acute kidney injury in the tropics. Ann Saudi Med 2011;31(5): 451-456.

17. Burdmann EA, Jha V. Acute kidney injury due to tropical infectious diseases and animal venoms: a tale of 2 continents. Kidney Int 2017; 91(5):1033-1046.

18. Mercado M, Acosta-Reyes J, Parra E, Guzmán L, Beltrán M, Gasque $P$, et al. Renal involvement in fatal cases of chikungunya virus infection. J Clin Virol 2018;103:16-18.

19. Mehta RH, Grab JD, O’Brien SM, Bridges CR, Gammie JS, Haan $\mathrm{CK}$, et al, Bedside tool for predicting the risk of postoperative dialysis in patients undergoing cardiac surgery. Circulation 2006;114(21):2208-2216.

20. Singh P, Rifkin DE, Blantz RC. Chronic kidney disease: an inherent risk factor for acute kidney injury? Clin J Am Soc Nephrol 2010;5(9):1690-1695.

21. Inbanathan J, Lavanya BU. Clinical Profile of Renal Involvement in Acute Gastroenteritis Patients. Int J Sci Stud 2016;4(8):48-52.

22. Arora P, Rajagopalam S, Ranjan R, Kolli H, Singh M, Venuto $\mathrm{R}$, et al. Preoperative Use of Angiotensin-Converting Enzyme Inhibitors/Angiotensin Receptor Blockers Is Associated with Increased Risk for Acute Kidney Injury after Cardiovascular Surgery. Clin J Am Soc Nephrol 2008; 3(5): 1266-1273. 